\title{
Empreendimento econômico solidário e empresa social: ampliando abordagens e integrando conceitos no diálogo Norte-Sul
}

\author{
Adriane Vieira Ferrarini \\ Universidade do Vale do Rio dos Sinos (Unisinos), São Leopoldo, Brasil \\ Email:adrianevf@unisinos.br \\ Jean-Louis Lavile \\ Conservatoire National des Arts et Métiers (CNAM), Paris, Francia \\ Email: jean-louis.laville@cnam.fr

\section{Isabelle Hillenkamp}

Centre D’études en Sciences Sociales sur les Mondes Africains, Américains et

Asiatiques (CESSMA), Paris, Francia

Email: isabelle.hillenkamp@ird.fr

\section{Luiz Inácio Germany Gaiger}

Universidade do Vale do Rio dos Sinos (Unisinos), São Leopoldo, Brasil

Email: mariliav@unisinos.br

\section{Marília Veríssimo Veronese}

Universidade do Vale do Rio dos Sinos (Unisinos), São Leopoldo, Brasil

Email: gaiger@unisinos.br

Resumo:Iniciativas econômicas que enfatizam a criação de valor social ampliaram-se significativamente nas últimas décadas, requerendo a construção de conceitos e tipologias que permitam seu conhecimento, comparação e análise em âmbito mundial - objetivo do projeto de pesquisa intitulado "International Comparative Social Enterprise Models” (ICSEM). Neste trabalho, pesquisadores vinculados ao ICSEM visam analisar o empreendimento de economia solidáriatípico do Sul - como um caso de empresa social a partir doscritérios e indicadores do Modelo EMES (europeu), identificando convergências e divergências. Trata-se de estudo teórico, o qual concluiu que o empreendimento econômico solidário é um caso de empresa social. Contudo, traços distintivosda economia solidária(tais como: autogestão, protagonismo dos próprios excluídos e racionalidade econômica substantiva)suscitamredefinições em critérios sociais, econômicos e políticos, possibilitando, por um lado,um novo modelo para os empreendimentos e, por outro, uma dimensão mais ampla e multicultural na análise teórica de empresas sociais.

Palavras-chave: Indicadores; modelos; comparação; pesquisa 


\title{
Emprendimiento económico solidario y empresa social: Ampliando enfoques e integrando conceptos en el diálogo Norte-Sur
}

Resumen:Las iniciativas económicas que enfatizan la creación de valor social se han ampliado significativamente en las últimas décadas, requiriendo la construcción de conceptos y tipologías que permitan su conocimiento, comparación y análisis a nivel mundial - objetivo del proyecto de investigación titulado “International Comparative Social Enterprise Models” ICSEM). En este trabajo, investigadores vinculados al ICSEM buscan analizar el emprendimiento de economía solidaria - típico del Sur - como un caso de empresa social a partir de los criterios e indicadores del Modelo EMES (europeo), identificando convergencias y divergencias. Se trata de un estudio teórico, el cual concluyó que el emprendimiento económico solidario es un caso de empresa social. Sin embargo, rasgos distintivos de la economía solidaria (autogestión, protagonismo de los excluidos y racionalidad económica sustantiva) suscitan redefiniciones en criterios sociales, económicos y políticos, posibilitando, por un lado, un nuevo modelo para los emprendimientos y, por otro lado, una dimensión más amplia y multicultural en el análisis teórico de las empresas sociales.

Palabras clave: Indicadores; modelos; comparación; investigación

\section{Solidarity economic enterprise and social enterprise: Broadening approaches and integrating concepts in the North-South dialogue}

\begin{abstract}
Economic initiatives that emphasize the creation of social value have significantly increased in recent decades, requiring the construction of concepts and typologies that allow their knowledge, comparison and analysis worldwide, which is the purpose of the research project "International Comparative Social Enterprise Models” (ICSEM). In this paper, researchers involved in the ICSEM project aim to analyze the solidarity economic enterprise - typical from Southern countries - as a case of social enterprise according to the criteria and indicators of the EMES Model (European), identifying correspondences and differences. This is a theoretical study, which concluded that the solidarity economic enterprise is a case of social enterprise. However, distinctive characteristics of solidarity economy (such as: self-management, protagonism of excluded people and substantive economic rationality) evokes adaptations in social, economic and political criteria, enabling a new model for solidarity enterprises and also a broader and multicultural dimension in the theoretical analysis of social enterprises.
\end{abstract}

Key words: Indicators; models; comparison; research

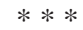

\section{Introdução}

Ao redor do mundo, crises globais cíclicas reduzem sistematicamente a capacidade de regulação social e econômica dasestruturas instituídas. A década de 1980, a chamada “década perdida”, demarcou um dessestípicos períodos de crise, com altos índices de desemprego e recessão mundial. 
Esta conjuntura, particularmente desfavorável aos trabalhadores, engendrou diferentes reações na luta pela subsistência e pela coesão social (Singer, 2006; Pinheiro,2016).

Ao Norte, em especial no continente europeu, emergiram iniciativas que passaram a constituir o campo da "economia social”, o qual se refere às atividades econômicas que buscam democracia econômica associada à utilidade social, são movidas por um sentido de solidariedade e, concretamente, valem-se da hibridação de recursos mercantis, não-mercantis e nãomonetários (Defourny, 2009). A economia social é formadaprincipalmente por empresas sociais e organizações do terceiro setor, cuja finalidade não é o lucro, mas sua missão social. Tais organizações foram herdeiras de iniciativas de tipo cooperativo e mutualista nascentes no início de século XIX, típicas das sociedades ocidentais e procedentes simultaneamente de matriz regulatória (ligada à emergente sociedade de mercado) e emancipatória (ligadas a perspectivas dos socialistas utópicos)(Defourny, Develtere \& Fonteneau,2001). O conceito de empresa social não compete a todo o campo da economia social, mas ajuda a identificar a dinâmica empresarial que está no cerne do terceiro setor (Defourny \& Nyssens, 2013).

Ao Sul, particularmente no Brasil, a economia solidária se constituiu como uma das formas de resistência dos trabalhadores ao desemprego, os quais passaram a associar-se para produzir de forma autônoma através de uma miríade de empreendimentos econômicos solidários(EES) no campo da produção, comercialização, consumo e financiamento(Gaiger, 2006; França Filho, 2006). Apesar de ser um "conceito amplamente utilizado no mundo, com acepções variadas que giram ao redor da ideia de solidariedade” (Gaiger \& Laville, 2009, p. 162), a economia solidária diferencia-se de outras iniciativas do campo da economia social fundamentalmente por certas características, como a propriedade coletiva do meio de produção, o protagonismo dos próprios trabalhadores no enfrentamento a múltiplas formas de exclusão e a autogestão do empreendimento (Veronese, Gaiger \& Ferrarini, 2017).

A dimensão política, entretanto, é o principal traço distintivo da economia solidária. De uma gênese interpretada como reativa, elalogo evidencioucaráter propositivo, sendo articuladora de instâncias políticas e de práticas em prol de um projeto societário mais justo e sustentável. Como consequência, a partir de meados da década de 1990 a economia solidária passou gradativamente a adquirir institucionalidade, constituindo-se rapidamente como organização econômica, movimento social e política pública. Estas múltiplas expressões alteram-se profundamente em suas configurações e dinâmicas em distintos países latino-americanos, mas de modo geral têm redundando na constituição de uma identidade própria e possibilitado crescente legitimidade institucional.

O século XXI trouxe consigo novos desafios sociais e ambientais e a agudização da instabilidade, contribuindo para o recrudescimento de arranjos socioeconômicos alternativos. O conhecimento, compreensão e análise desses arranjos tornaram-se objeto de estudo de pesquisadores de 
todo o mundo, visto que os aportes produzidos a partir de empresas tradicionais (voltadas à maximização do lucro) mostravam-se inapropriados.

Na Europa, surge em 1996 uma rede de pesquisadores individuais e centros de pesquisas que, em 2002, passou a denominar-seRede Europeia de Pesquisa EMES, cuja finalidadetem sido produzir conhecimento teórico e empírico pluralista, a partir de diferentes disciplinas e metodologias, em torno de conceitos que eles denominaram "SE" (considerando as iniciais da maioria dos termos em língua inglesa): social enterprise, social enterpreunership, social economy e solidarity economy.

No Brasil (estado do Rio Grande do Sul), em 1999 o Grupo de Pesquisa em Economia Solidária e Cooperativa (ECOSOL) foi criado com o objetivo deinvestigar experiências associativas e cooperativas baseadas na reciprocidade, inquirindo seu sentido alternativo e emancipatório.Ao longo dos anos, inúmeras pesquisas têm gerado aportes descritivos, analíticos e tipológicos sobreos EES.

Recentemente, estudos mais aprofundados e comparativos em torno da denominada"economia social e solidária”- termo bastanteutilizado internacionalmente e crescentemente incorporado pelas redes de pesquisa no Brasil -mostraram-se necessários a fim de agregar experiências e concepções desenvolvidas ao Norte e ao Sul. Tais estudos motivaram a criação do projeto de pesquisa denominado"International Comparative Social Enterprise Models” (ICSEM), coordenado pelo Belgian Science Policy Office (BELSPO),em parceria com a Rede EMES, com execução no período de 2013 a 2018.O objetivo do ICSEM é produzir uma tipologia de empresas sociais que reflita a diversidade presente, tanto no interior dos países envolvidos quanto internacionalmente, através da comparação de modelos e seus respectivos processos de institucionalização. A cobertura geográfica é a principal característica do Projeto, contando com a participação de 230 investigadores de 55 países da Europa Ocidental e Oriental, América do Norte, América Latina, Ásia e África, perfazendo 56 países.

Tendo finalidade comparativa, o ICSEMpartiu de um modelo de empresa social criado pela Rede EMESpara a identificação e caracterização dos vários tipos de empresas sociais.Talmodelofoi criado a partir dedados europeus relativosao final do século XX, podendo serquestionado, tanto com base nas novas formas de empresas sociais emergentes na Europa no contexto de crise do início do século XXI, comopor experiências de outras partes do mundo, a exemplo dos EES presentes no Brasil e em outros países latino-americanos.Por conseguinte, o Modelo EMES é tido como ferramenta metodológica e não como conceito único. No caso dos EES, ainda que partilhem de princípios fundamentais da economia social, há um conjunto não desprezível de diferenciações, as quais, agregadas à incipiência do debate brasileiro sobre o termo e conceito"empresa social”, levou pesquisadores do ICSEMà elaboração deste artigo, cujo objetivo é analisar o EES como um caso de empresa social, identificando convergências, divergências e possibilidades de ampliação conceitual e tipológica com 
relação aos critérios e indicadores do Modelo EMES. Em última instância, o textoanalisa a economia solidária sob aportes teóricos e tipológicos de empresa social consolidados no Norte, contribuindo simultaneamente para o enriquecimento de produções sobre o tema no Brasil e para a ampliação do escopo do referido Modelo e da teorização sobre empresa social.

Para tanto, o artigo,inicialmente, apresentará osfundamentos e limites das abordagens norte-americanas e europeias de empresa social. Posteriormente, valendo-se de aportes empíricos e teóricos produzidos pelo Grupo Ecosol ao longo de inúmeras pesquisas e publicações, serãoaprofundadascaracterísticas e especificidades dos EES a partir os critérios e indicadores do ModeloEMES.

\section{Abordagens teóricas de empresa social}

Concepções canônicas do campo das ciências econômicas, que se concentram na maximização do lucro através da criação de valor para os acionistas, mostraram-se inadequadas para a análise de empresas que criam valor social. Tal lacunavem sendo suprida pelas abordagens europeias e norte-americanas de empresas sociais. Independentemente das diferenças existentes entre as duas correntes de pensamento, ambas concordam em enfatizar a finalidade social da empresa, a capacidade de reinserção de desempregados no mercado de trabalho, a proposta de novos serviços locais e a revitalização dos territórios a partir da ajuda mútua entre a população e da promoção de metodologias inovadoras para o desenvolvimento local sustentável.

\section{As contribuições da Europa e da América do Norte}

Nos Estados Unidos, o conceito de empresa social data do início da década de 1990 e é ainda bastante amplo, sendo relevante distinguir duas grandes escolas: recursos provenientes do mercado (earned-income strategies) e inovação social (Defourny \& Nyssens,2013). A primeira, sistematizada por James Austin e colaboradores da Escola de Negócios de Harvard, destaca o uso de estratégias de mercado como meio para empresas sem fins lucrativos cumprirem sua missão social (Austin, Leonard, Reficco \& Wei-Skillern,2006). A segunda, inspirada na perspectiva schumpterianado empresário que inova para atender às necessidades sociais, considera que diferentes tipos de empresas podem contribuir para um objetivo social, não importando se elas são ou não organizações sem fins lucrativos (Dees, 1998; Salamon \& Young, 2002).

A aproximação entre essas duas correntes de pensamento conduziu à definição de empresa social a partir de sua missão social. Nesta perspectiva, o aumento de recursos provenientes de estratégias lucrativas é desejávelpara o cumprimento da missão, sem que necessariamente haja 
uma ligação com o tipo de atividade econômica, a estrutura de governança ou a dinâmica de inovação social. O reconhecimento do empreendedor social individual envolvido na criação de valor social é o que justifica e legitima a empresa social(Austin, Leonard, Reficco \& Wei-Skillern,2006).

A contribuição da Rede EMES, por sua vez, tem a originalidade de articular a missão social da empresa com sua estrutura de governança interna. $\mathrm{O}$ percurso histórico das empresas sociais europeias - e que as vincula às organizações da economia social - explica a importância dos critérios de participação e tomada de decisão, os quais não estão relacionados à propriedade do capital e aos limites de distribuição de lucros. Essa ligação entre a missão social e a estrutura interna de governança é a principal diferença entre as correntes norte-americanas e europeias (Defourny \&Nyssens, 2013).

A importância atribuída aos critérios de democracia econômica interna cria uma lacuna no que diz respeito aosmétodos de gestão do setor privado comfins lucrativos, predominantes nas abordagens norte-americanas. Tais critérios europeustornam possível considerar empresas sociais como parceiros legítimos em políticas públicas com certo grau de interação com o ambiente institucional, constituindo um canal para a difusão das inovaçõessociais produzidas(Defourny in Cattani, Gaiger, Hespanha \& Laville,2009). Já na abordagem norte-americana, a propagação da inovação social é considerada resultado da expansão ou multiplicação de empresas sociais através da utilização de recursos e de estratégias de mercado, do apoio das fundações e dodinamismo dos empresários.Em comum, as abordagens norte-americanas e europeias consideram as empresas sociais como organizações privadas, porém localizadas na interface com a esfera pública, uma vez que contribuem para a definição de problemas sociais que se tornam objetos de debate e de intervenção(Defourny \& Nyssens,2013).

\section{Limites das abordagens de empresa social}

O debate europeu e norte-americano, bem como a necessidade de diálogo com diferentes realidades mundiais, evidencia a existência de três limites das abordagens de empresa social. O primeiroé de ordem políticae tem a ver com as relações de poder e interesses envolvidos na própria definição das demandas sociais e da construção de soluções, muitas vezes materializadas através das empresas sociais. Há sempre o risco de as definições e decisões serem tomadas por agentes instituídos, que possuem acesso a informações, recursos e poder, limitando processos e resultados emancipatórios, quando não reproduzindo lógicas dominantes.A análise não é centrada na natureza e legitimidade dos destinatários, em seu projeto político, tampouco nas relações sociais que estabelecem. As empresas sociais afirmam contribuir para uma missão social e, portanto, para a criação de valor social, mas a relação entre estas empresas e o debate público é evitada (França Filho \& Laville, 2004). 
Fica claro que a definição europeia inclui o fato de a iniciativa vir de um grupo de cidadãos, mas a empresa social em geral limita o funcionamento democrático a uma igualdade formal entre os membros garantida pelo aspecto legal, sem explicar os métodos pelos quais essas relações igualitárias se tornam realidade. Em que medida a empresa social se compromete ou deveria se comprometer com os anseios dos grupos excluídos e com o seu empoderamento, elementos imprescindíveis para a missão de transformação social com a qual a empresa social se diz implicada?

A reflexãoacerca da concepção de esfera pública contribui para clarificar este limite político da empresa social. A dimensão pública aqui referida é melhor compreendida a partir do sentido dado porHannah Arendt e Jürgen Habermas, para quem o espaço público se constitui como uma estrutura aberta, não sendo possível delimitar seus limites e fronteiras previamente, tampouco confundi-lo com instituição, organização ou qualquer sistema normativo. O espaço público é, por excelência, o espaço do fazer político e da esfera pública, da construção daquilo que é comum, sendo esse "comum” não necessariamente harmônico. "Livre agir é agir em público, e público é o espaço original do político” (Arendt,1999, p.11).Sendo possível verificar a congruência ou incongruência entre o que é estabelecido nos sistemas institucionaise a experiência vivida cotidianamente, esfera pública e esfera privada não estão desconectadas; pelo contrário, apresentam ressonânciasmútuas. A esfera pública capta e realça as temáticas existentes na esfera privada, problematizando-as e trazendo-as para o debate público. A esfera privada, por sua vez, incorpora os debates e agrega informações que influenciam na vida cotidiana e possibilitam refletir sobre a mesma(Losekann,2009).

Nessa perspectiva, fica claro que as atividades econômicas da empresa social são inseparáveis ??da dimensão institucional, a qual diz respeito fundamentalmente a dois aspectos. O primeiro se refere àlógica instituinte,pela qual os atores criam e consolidam a atividade em execução através da emissão de regras, demonstrando assim a sua capacidade para gerar bens comuns e até mesmo o seu desejo de transformação. $\mathrm{O}$ segundo consiste noquadro institucional,que envolve um conjunto de normas pré-estabelecidas em diferentes escalas e registros, formalizados juridicamente ou não, os quais influenciam a ação (Ostrom, 2005). Portanto, a reintegração do aspecto institucional na análise requer uma perspectiva complexa, capaz de reconhecer elementos que tornam a ação coletiva possível, mas também a limitam.

O segundo limite é de ordem econômica e se refere à usual presença dos vários setores (Estado, sociedade civil e mercado) na constituição ou dinâmica das empresas sociais, sem uma diferenciação acerca da racionalidade, intencionalidade e do ethos de cada um. Empresas de mercado que atuam na criação de valor social sob o imperativo e primazia do lucro e aquelas que têm sua intencionalidade ético-política e finalidade precípuas voltadas ao social possuem diferenciações que precisam ser explicitadas. Ainda que ambas criem valor social, é necessário reconhecer que, no caso 
das empresas de mercado, os interesses sociais são submetidos aos corporativos, sendo comum que a apropriação dos resultados conflua significativamente para a empresa. Além disso,a empresa social se aproxima mais do risco, o que pode comprometer sua missão e os processos de criação de valor social.Quanto ao processo, a participação da população tende a ser caracterizada como de baixa intensidade. Análises indiscriminadas criam o risco de incorporação da empresa social a uma racionalidade instrumental que, não apenas absorve ou reduz suas potencialidades transformadoras,quanto alimenta a dinâmica de acumulação expansionista geradora - numa análise transescalar - da própria exclusão que a empresa se propõe a enfrentar (Ferrarini, 2016).

Neste caso, a possibilidade de interação positiva entre a esfera econômica e a social é questionável. Em geral, o "social” é definido como resultante denecessidades não satisfeitas pelo Estado ou pelo mercado, mas a escolha de uma missão dentro deste vastocampo pode ser feita por um empreendedor social ou por outros tomadores de decisão na empresa, conforme destacado na limitação política. De modo mais geral, essas abordagens não questionam o lugar da economia e da empresa na sociedade (Hulgård, 2010; Ferrarini, 2013). A economia é definida como a atividade de prestação de bens e serviços de forma contínua. Essa visão torna possível a distinção entre empresas sociais e outros tipos de organizações com uma missão social, mas sem uma atividade "econômica”, como as fundações. No entanto, ela não permite que se aborde a maneira pela qual são instituídas as práticas de produção, troca, consumo e financiamento, ou que se analise a ordem política pela qual as empresas sociais operam.

Esta visão pode, dentre outras consequências, reduzir a institucionalização das empresas sociais àsformas jurídicas existentes- cooperativas, associações, sociedades mutualistas - oua novos formatos reconhecidos em determinados países.Com isso, empresas sociais informais - que não se encaixam em qualquer legislação - são negligenciadas ou tendem a ser vistas como mera variação das modalidades de referência (Fonteneau et al, 2011apud Gaiger, 2013, p.10). Contudo, em muitos contextos, tais empresas representam um dos casos mais importantes de empresa social. Esta questão jurídicarepresenta oterceiro limite das referidas abordagens. A importância de empresas sociais informais devese, não apenas ao seu elevado número - especialmente no contexto latinoamericano - mas tambémàs reflexões que suscita na medida em que muitas destas empresasnão pretendem se formalizar; elas têm sua própria lógica instituinte através de regras internasde gestão, manifestadas na sua capacidade de auto-organização.

Se não se considera a lógica instituinte, a qual pode estar localizada na economia informal ou naformal, a análise de empresas sociais corre o risco de transformar-se em um componente deabordagens neomodernizadoras, assumindo implicitamente uma tendência para a formalização das empresas sociais (Hillenkamp, ??2013). A análise desenvolve uma visão diferente de empresa, mas não se centra nas relações 
entre as esferas política e econômica, tampoucoquestiona o quadro institucional em que a atividade da empresa é conduzida. Trata-se de permitir uma divisão entre três esferas de atividade - econômica, social e política cujas fronteiras e interações são apenas parcialmente questionadas.

Uma abordagem institucional que não se limite ao quadro jurídico existente possibilita restaurar o significado e alógica que se cristalizam em formas organizacionais particulares, legalmente reconhecidas ou não (Gaiger, 2013). Refletindo sobre as categorias “social” e "empresa” a partir do lugar da economia na sociedade,do debate público e da democracia, encontra-se na economia solidária uma contribuição diferente e complementar às abordagens referidas, tanto no âmbito teórico quanto empírico.

\section{Empreendimentos econômicos solidários: um caso de empresa social?}

Empresas sociais inspiradas pelo modelo norte-americano - como, por exemplo, a Social Enterprise Knowledge Network, ligada à Harvard Business School - ocupam um lugar de menor destaque no debate público e políticolatino-americano.Na América Latina, são as redes de empreendimentos solidários populares que vinculam a organização democrática das práticas econômicas ao posicionamento na esfera pública (França Filho,2006) e que desempenham um papel significativo na mudança institucional e na transformação social.

Os EES latino-americanos surgiram a partir da incapacidade ou inconformidade de segmentos populacionais adaptarem-se às condições do capitalismo periférico e às formas de sociabilidadeque ele produz (Gaiger, 2013), em contextos de vulnerabilidade sociale destinados,principalmente, à subsistência. Contudo, tais empreendimentos são herdeiros e se integram em um conjunto mais vasto de práticas econômicas que sempre subsistiram nos países periféricos,

"Escoradas em laços de reciprocidade, nas quais a produção material subordina-se a necessidades coletivas e guarda um sentido primordialmente social. Sobretudo a partir da economia popular, ganharam forma experiências genuínas na América Latina, como alternativas para trabalhadores rurais e urbanos, indígenas e imigrantes que valorizaram as práticas autóctones de ajuda mútua e fizeram seu sentimento comunitário prevalecer contra a desordem introduzida pelo capital” (Gaiger \& Laville, 2009, p. 163).

A partir da década de 1990 a economia solidária veio a abarcar, em seu processo de expansão, diversas categorias sociais e variadas modalidades de organização, como unidades informais de geração de renda, associações de produtores e consumidores, sistemas locais de troca, comunidades produtivas autóctones e cooperativas, dedicadas à produção 
de bens, à prestação de serviços, à comercialização e ao crédito (Veronese, Gaiger \& Ferrarini, 2017).

Movido pela necessidade, de baixo para cima e com uso de escassos recursos materiais e imateriais, o empreendedorismo associativo que caracteriza os EES se diferencia radicalmente da tradicional concepção do empreendedorismo de oportunidade de matriz schumpeteriana, o qual é protagonizado por umsujeito empreendedor que vale-se de uma excepcional capacidade criadora, descobre um nicho de mercado, toma iniciativas e corre riscos.

Ainda que necessidade e oportunidade não sejam absolutamente incompatíveis e que esta dicotomia desconheça os tipos intermediários ou híbridos(Gaiger; Correa 2010), é possível identificar distintas racionalidades subjacentes nos tipos de empreendedorismo. Se o empreendedorismo convencional se pauta numa racionalidade econômica instrumental que supõe a lógica da ação individual,as experiências da economia solidária demonstram que o empreendedorismo depende de fatores contextuais cuja natureza não é somente econômica, mas igualmente política e ideológica. Oempreendedorismo associativo,portanto, expressa uma racionalidade substantiva, na qual a reciprocidade e a redistribuiçãosão duas formas de intercâmbio na produção da vida, para além da mercantil (Polanyi, 2011; Hillenkamp, 2013).

São a cooperação e a colaboração - denominadas porRazeto (1993) como "fator C" - que permitem economias de escala, economias de associação e externalidades coletivas no decurso de ação, as quais conduzem à redefinição dos conceitos de eficiência e eficácia.Os EES simultaneamente reativam a solidariedade e a cooperação através da passagem de táticas de sobrevivência para estratégias empreendedoras e solidárias (Certeau, 1980).A primazia da solidariedade em tais empreendimentos manifesta-se no envolvimento de seus membros com a gestão cotidiana, na socialização dos recursos produtivos e na adoção de princípios de equidade. Quando estendida a seu entorno, a solidariedade pode estimular práticas ampliadas de reciprocidade, nas quais as vivências concretas de gestão do bem comum conferem um novo valor às noções de justiça e de interesse público. Por tais características, particularmente no Brasil, Bolívia, Equador e Nicarágua, os EES têm dado origem a novas políticas públicas ou a marcos legais através de uma visão plural da economia (Wanderley et al, 2015).

Consequentemente, os ganhos auferidos nos EES também não se restringem à dimensão econômica, pois a provisão da subsistência é inseparável de efeitos virtuosos, extraeconômicos e sistêmicos da cooperação. A economia solidária não se trata apenas de uma forma de produção da vida material, mas de formas alternativas de construir vínculos e práticas políticas que reconstroem redes de proteção primária e que são capazes de reduzir situações de vulnerabilidade, fortalecer identidades e promover cidadania. O agir coletivo da economia solidária institui, então, 
novos sujeitos no mundo do trabalho, nas estratégias de classe e nas lutas sociais, em resposta a anseios de bem-estar, reconhecimento e vida significativa (Cattani et al., 2009; Gaiger, 2004; Pinto, 2006; Singer \& Souza, 2000).

Muitos conceitos têm sido desenvolvidos para os EES, bem como características elencadas do que seria considerado seu tipo ideal (Razeto, 1993; Gaiger,2013), não com o objetivo de normatizar ou padronizar, mas para criar critérios substantivos capazes, até mesmo, de incluir experiências que por ventura se diferenciem de formatos convencionais.

Esta diversidade de práticas econômicas engendradas sob princípios de solidariedade ao redor do mundo - e particularmente em países que compõem o Projeto ICSEM -requer quadros metodológicos e analíticos que transcendam as referências produzidas a partir das empresas sociaisdo Norte, porém sem desconsiderá-los. Para tanto, se aprofundará a seguir os indicadores dos EES, vinculando-os à abordagem europeia, particularmente ao Modelo EMES de empresa social.

\section{Modelo EMES de empresa social e sua aplicação a empreendimentos econômicos solidários}

Neste trabalho, a busca de diálogo entre abordagens do Norte e realidades do Sul levou pesquisadores a analisar o EES a partir da aplicação do Modelo EMES, identificando correspondências, divergências e possibilidades de ampliação em critérios e indicadores. A multidimensionalidade dos indicadores(sociais, econômicos e políticos) é imprescindível, visto que critérios econômicos, em geral concebidos a partir de uma lógica mercantil, são insuficientes para a definição e análise de empresas sociais. Cabe ainda destacar que, tal como nas definições latinoamericanas, os indicadores do Modelo EMES constituem o tipo idealde EEScomo construção abstrata - e nãocomo critérios normativos.

\section{Indicadores econômicos}

O Modelo EMES elencou os seguintes indicadores econômicos para empresas sociais: (i) atividade contínua que produz bens e/ou vende serviços; (ii) significativo risco econômico e (iii) valorização do trabalho. Na adaptação às especificidades presentes nos EES, os dois primeiros foram alterados e terceiro foi mantido. A seguir, serão explicitados conceitos acerca de cada um desses indicadores e inflexões produzidas a partir da realidade da economia solidária.

O primeiro indicador é a hibridização de princípios econômicos e a lógica de solidariedade. Trata-se da produção contínua de bens ou serviços como um indicador econômico a partir da abordagem da economia substantiva de Karl Polanyi (Polanyi, Conrad \& Pearson,1975), a fim de distinguir empresas sociais e organizações sem fins lucrativos voltadas à defesa de 
interesses corporativos ou à redistribuição de recursos, tais como as fundações. No entanto, este indicador não faz distinção entre empresas cujasatividades de produção de bens e serviços seguem apenas a lógica do mercado e aquelas que se pautam em outros princípios econômicos. Isso faz com que seja possível incluir empresas sociais pautadas no modelo norte-americano de mobilização de recursos mercantis (Defourny \& Nyssens,2013),com tendênciaa se deixar de foracaracterísticas essenciaisdosEES, tais comoa pluralidade de princípios econômicos e a existência de uma lógica de solidariedade.

Polanyi (2011)refutou a concepção canônica da racionalidade econômica como reduzida ao interesse material individual e centrada no mercado,propondo a existência de princípios não mercantis e não monetários vinculados à economia. O primeiro princípio é a redistribuição, que corresponde à interdependência em sistemas centralizados, atuando em diferentes níveis, cujos recursos advêm da tributação realizada por uma autoridade central e da sua alocação feita com base em regras por ela estabelecidas. $\mathrm{O}$ segundo refere-se à reciprocidade, umprincípio de complementaridade instituída em diferentes níveis por agrupamentos simétricos, nos quais os membros praticam uma espécie de mutualismo. O terceiro princípio é a economia doméstica e consiste em tipos cambiantes de interdependência dentro de unidades fundadas sobre a autossuficiência (Hillenkamp, ??2013; Servet, 2013), produzindo recursos para seu próprio uso.Finalmente, o mercado corresponde aos tipos de interdependência automaticamente criados entre compradores e vendedores através de flutuações de preços. Esses princípios de integração econômica não são considerados simplesmente como formas de intercâmbio de recursos, mas como processos e lógicasinterdependentes, tornando-se o elemento fundamental da análise econômica que integra diferentes dimensões da vida individual e coletiva (Polanyi, 2011).

Os princípios enunciados por Polanyi restabelecem uma visão de economia política, a qual questiona as estruturas institucionais e políticas,das quais a empresa social é parte quando mobiliza vários tipos de recursos. Contudo, a complexidade dos sistemas sociais faz com que tais princípios sejam portadores deambiguidades. Por exemplo, a economia doméstica, quando produzidaem sistemas patriarcais,pode ser questionada por reproduzir relações hierárquicas de poder pautadas na diferenciação por gênero, dentre outras possibilidades de opressão ou classificação social (Hillenkamp, 2013). Da mesma forma, o princípio da reciprocidadenão é necessariamente uma categoria positiva, podendo ser mobilizado de forma coercitiva. É apenas quando a reciprocidade é voluntariamente instituída, que este princípio pode assumir um caráter igualitário e constituir a base de um processo democrático participativo ou deliberativo. A redistribuição, por sua vez,tanto pode ser associada a métodos de democracia representativa, inclusive em nível local, quanto pode ser gerenciada de forma autoritária.

Nessa lógica, o EES tende a substituira economia doméstica, prioritária na economia popular, através da reciprocidade voluntariamente 
instituída em bases igualitárias.Este tipo de empresa social é baseado em uma combinação, tanto de princípios econômicos, quanto de acordos e regras formais e informais(Nyssens,1996).

O segundo indicador é a consistência do compromisso econômico, social e ambiental. A fim de possibilitar distinções entreempresa sociale administração pública, um dos indicadores do Modelo EMESdiz respeito ao nível de risco ou compromisso econômico assumido pelos fundadores da empresa. Contudo, tal análise parece insuficiente se o econômico não for considerado como parte de uma totalidade que inclui o compromisso social e ambiental.

O consenso mínimo sobre a agenda do desenvolvimento sustentável, a partir do relatório de Brundtland (1987) para as Cimeiras da Terra em 1992, 2002 e 2012, adveiodo reconhecimento acerca da urgência de integrar as dimensões econômicas, sociais e ambientais nas atividades humanas. Parece difícil imaginar que as empresas sociais poderiam se envolver em atividades economicamente arriscadas ou em atividades prejudiciais do ponto de vista social ou ambiental e, em seguida, reinvestir os lucros geradosem sua missão social.

Os membros de EES e muitos fundadores de empresas sociais objetivam a coerência entre os vários domínios da atividade produtiva, preocupam-secom o impacto geradoebuscam dar respostas efetivas aos problemas sociais e ambientais. Por exemplo, é comum a preferência por pigmentos naturais ou pela agroecologia, mesmo que ela venha a aumentar os custos de produção num primeiro momento (já que, mais tarde, estes produtos tendem a ser valorizados em mercados específicos). Ao submeter tais escolhas a espaços internos para a discussão democrática, as empresas também podem desenvolver métodos para priorizar os objetivos econômicos, sociais e ambientais no nível local, oferecendo uma resposta para a principal preocupação dos ecologistas, que é a insuficiência de ações concretas que integrem as múltiplas dimensões (Van Griethuysen,2010).

O terceiro indicador é valorização do trabalho. O Modelo EMES identifica um nível mínimo de trabalho remunerado como o último critério econômico da empresa social. Aqui, novamente, a experiência doEES, em especial da economia popular, requer que se dê um passo além, estabelecendo a valorização do trabalho como princípio comum.

A economia popular tem sido definida como "atividades econômicas e práticas sociais desenvolvidas por grupos populares, a fim de garantir, pelo uso de sua própria força de trabalho e dos recursos disponíveis, a satisfação das necessidades básicas, tanto materiais quanto imateriais" (Sarria Icaza \& Tiriba,2006, p. 259). Esta abordagem tem o mérito de redescobrir formas de organização popular com um componente econômico embutido em suas relações sociais e culturais, as quais foram invalidadas por dois séculos - tidas como arcaicas, ultrapassadas e condenadas ao desaparecimento devido à modernização. Esta economia popular não pode 
ser conceituada meramente como reativa e funcional à economia formal, um complemento obrigatório para o expansionismo capitalista desenfreado, tal como sugere a expressão “capitalismo de pés descalços” (Soto,1997). Para Coraggio (2006), a economia popular é a economia do trabalho, em oposição à economia do capital, porque implementada com base na lógica do trabalho e da reprodução da vida na unidade doméstica.

O EES, ancorado na economia popular, toma posição contra a divisão social entre capital e trabalho, pois limita a contrataçãode trabalhadores externos à organização. Tal tipo de empreendimento tende a gerenciar a organização do trabalho e a determinar a sua remuneração sob formas democráticas de decisão, independentemente das ações do capital social, conforme ilustrado particularmente pelas referências à autogestão e a modelos cooperativos.

\section{Indicadores sociais}

Tão importante quanto os indicadores econômicos, os sociais foram assim definidos no Modelo EMES: (i)ter o objetivo explícito de beneficiar a comunidade; (ii) ser uma iniciativa de grupo de cidadãos ou organizações da sociedade civil e (iii) ter uma distribuiçãolimitada dos lucros. Na adaptação à realidade dos EES, tais indicadores foram redefinidos da seguinte forma: (i) objetivo de transformação e reparação; (ii) solidariedade democrática no empreendimento econômico solidário e (iii) autonomia.

O primeiro indicador é o objetivo de transformação e reparação. A missão social das empresas sociais- referidano Modelo EMES como um serviço à comunidade ou a um grupo de beneficiáriose aqui aplicada aosEES - pode ser especificada e identificadaatravés do duplo objetivo de transformação e reparação. Motivados pelo desejo de minimizar expressões da questão social econstruirum mundo mais igualitário, os trabalhadores deEESbuscamsimultaneamente atingir os dois objetivos, pois a contestação deregras e valores não pode ser vista separadamente à melhoria das condições de vida (Blanc \& Fare,2012). Esta concepçãoadvém da importância atribuída pelos empreendedores solidários à democratização da economia através de uma participação cidadã pautada na constatação de que o espaço excessivo ocupado pelo capitalismo financeiro e patrimonial é,na atualidade, uma causa essencial de desemprego e aumento da pobreza.

O desejo de transformação de longo prazo, combinada com o pragmatismo de curto prazo, gera uma concepção de mudança social que não tem a pretensão de se constituir comouma nova totalidade que rompa com determinações atuais, mas privilegiaa melhoria das condições de vida (Gaiger, 2006). Esta atenção para a dimensão humana da mudança socialtambém é inspirada pelo antiglobalismo, pelo qual um outro mundo a ser inventado já está presente neste mundo. Seu lema, “resistir e construir", transposto para a dimensãoeconômica, supõe que não se podecontar com outro sistema global, mas reinventar alternativas plurais nos espaços cotidianos de produção e reprodução da vida. 
O segundo indicador é a solidariedade democrática no empreendimento econômico solidário.Os objetivos de reparação e transformaçãosocial presentes noEES são mantidos e legitimados substantivamente pelo desejo de democratizar, expresso na prática através da solidariedade de baixo para cima, não se reduzindo aos resultados econômicos. Esta solidariedade, no que diz respeito às formas adotadas, não é a solidariedade tradicional herdadapor determinados grupos que podem reforçar hierarquias fundadas na idade ou sexo (Razeto, 1993). Além disso, também se difere da solidariedade filantrópica desenhada a partir da visão de uma sociedade ética, na qual os cidadãos motivados pelo altruísmo cumprem os seus deveres no que diz respeito aos mais pobres, numa base voluntária.No que diz respeito às pessoas envolvidas, esta é uma solidariedade tanto horizontal (destinada a grupos sociais), quanto transversal (que inclui as gerações futuras). Há, portanto, um desejo de lutar contra as desigualdades e pela justiça social, integrando os aspectos ambientais.O EES é baseado numa solidariedade que pode ser qualificada como democrática no sentido em que emerge de um postulado da igualdade ancorado na ordem política e transposto para a vida social e econômica.

Como corolário, a luta contra a pobreza não é a prioridade, ao contrário de outras configurações de empresas sociais. Também não se trata de mostrar compaixão e bondade para com os seus beneficiários, como é o caso de instituições de caridade. A economia solidáriapossibilita que as pessoas afetadas por um problema possam assumir o controle de sua resolução, assim como ocorre em iniciativas de empreendedorismo individual e de desenvolvimento comunitário. O critério é a participação ativa dos associados na definição e na implementação do objetivo do EES.

Assim, a proteção obtida pela ação coletiva é valiosa, porque é um vetor de emancipação ou autorrealização. A análise de Fraser (2011) explicita claramente esta configuração especial. Com base em Polanyi, que insistiu sobre os efeitos devastadores da sociedade de mercado e que mostrou como os grupos sociais se protegemcontra esse perigo, Fraser observou com pertinência que esta proteção pode promover tanto a dominação quanto a emancipação. A ideia de emancipação repousa nas lutas contra a escravidão dos povos não europeus sob o jugo colonial, mas também engloba exploração, dominação e opressão provenientes das desigualdades na relação entre capital e trabalho. Contemporaneamente, as pautas das lutas emancipatórias pluralizam-se, abrangendo questões de gênero, ambientalistas, dentre outras, inclusive contra formas de proteção social que também expressam dominações.

A autoraatribuiu maior complexidade ao duplo movimento de Polanyi (mercantilização - proteção), convertendo-o em um triplo movimento (mercantilização - proteção-emancipação). Neste quadro teórico, todas as empresas sociais organizam formas de proteção. O EES, por sua vez, tenta integrar proteção e emancipação. Em outras palavras, aperspectiva solidária enfatiza a importância da emancipação e da implementação de ações que articulam proteção e emancipação, ao invés de escolher um entre ou o outro. 
O terceiro indicador é autonomia. A autogestão reivindicada no funcionamento interno do EES está indissociavelmente ligada à autonomia na tomada de decisões e no acesso ao conhecimento estratégico, a partir da lógica instituinte que articula ajuda mútua e dinâmica de transformação social. Se o EES mantiver relações com outras organizações e receber recursos para obter acesso a mercados, financiamentos ou conhecimento técnicos ou gerenciais, este auxílio não deve causar a perda de controle da organização. OEES não deve tornar-se mero executor de programas do governo ou de projetos sociais de fundações privadas.”As empresas sociais são criadas por um grupo de pessoas em função de um projeto específico e são controladas por essas pessoas (...). Elas têm o direito de fazer suas vozes serem ouvidas” (Defourny \& Nyssens, 2013, p. 7).

\section{Indicadores Políticos}

Com relação à dimensão política, o Modelo EMES definiu os seguintes indicadores:(i) alto grau de autonomia; (ii) faculdade de decisão não baseada na propriedade de capital e (iii)natureza participativa, a qual envolve diferentes processos da atividade.Ao longo do debate entre pesquisadores do Norte e do Sul, percebeu-se a necessidade da criação de indicadores que permitissem a elucidação e análise da dimensão política nos EES, quais sejam: (i) dimensão pública do empreendimento; (ii) espaços públicos intermediários e (iii) empreendedorismo institucional e enraizamento político.

O primeiro indicador é a dimensão pública. O EES não tem apenas um papel econômico, mas participa da formulação de demandas e intervenções sociais a partir da já referida concepção de esfera pública comoespaço aberto e instituinte. As necessidades sociais não são identificadas através domarketing, tal como ocorre em iniciativas promovidas pela base da pirâmide (Prahalad, 2004); elas são apreendidas graças amicroespaços públicos autônomos, nos quais a deliberação torna possível redefinir os interesses e valores dos participantes (Hillenkamp \& ??Bessis,2012). Tais espaços, criados com base na proximidade, caracterizam a dinâmica participativa doEES, que vai além da igualdade jurídica dos membros. A manutenção dessa dinâmica, a longo prazo, requer uma atenção especial à ameaça de isomorfismo institucional criada pelas pressões da atividade econômica, uma das razões do abandono do ideário e da prática da autogestão no passado (Singer,2006).

O segundo indicador se refere a espaços públicos intermediários.A sustentabilidade dos micro-espaços públicos autônomossó pode ser alcançada se o quadro institucional for alterado, enfrentando a discriminação negativa a que os trabalhadores são sujeitos. Agrupamentos territoriais e setoriais e a criação de fóruns ou arenas mais amplas de debate são,portanto,espaços públicos intermediários essenciais para estimular o fortalecimento da economia solidária. Instituições demediação, representação e apoio são ainda mais relevantes para osEES, uma vez que 
geram aprendizado e promovem ganhos materiais e extraeconômicos (França Filho \& Laville, 2006; Gaiger, 2006).

A injeção de dinamismo em espaços públicos autônomos, tanto em nível micro quanto intermediário, é essencial para as estratégias econômicas não-capitalistas, protagonizadas pelas classes populares e média, face os excessos da economia dominante. Tais espaços públicos são também decisivos para a renovação do envolvimento dos cidadãos, considerando a insuficiência da democracia representativa.

O terceiro indicador é empreendedorismo institucional e enraizamento político. Os EES também se agrupam ou associam, pois seria ingênuo acreditar que poderiam impor-se através do seu desempenho econồmico. Eles constantemente sofrem com as discriminações negativas inerentes ao quadro institucional,em sentido amplo. Mudanças institucionaissão absolutamente necessárias, principalmente no âmbito jurídico e nas políticas públicas, as quais precisam ser desconstruídas (através da deslegitimação de hierarquias e de poderes instituídos) e reconstruídas (através do reconhecimento de atividades anteriormente ignoradas).

A açãoem prol de mudanças institucionais foi denominada de “empreendedorismo institucional” (Lawrence \& Suddaby,2006) e sua importância foi destacada pela UNESCO, a qual estipulou, na Declaração Universal sobre a Diversidade Cultural de 2001 que, diante de uma concentração oligopolística, os Estados devem associar, de forma estreita, os diversos setores da sociedade civil. Enquanto a literatura sobre empreendedorismo institucional concentrou-se em organizações como um todo, estudos de caso nos setores médico (Levy \& Scully, 2007) e ambiental(Quéinnec,2007) enfatizam o papel das associações (Rival, Eynaud \& Gautier, 2008). Nessa perspectiva, EESsão certamente uma das áreas a serem incorporadas.

Por isso, é crucial analisar o enraizamento político, ou seja, as interações entre as iniciativas da sociedade civil e as legislações e políticas públicas.EES, assim como outras iniciativas, podem influenciar os métodos de ação pública, ao mesmo tempo em que são padronizados pelas autoridades públicas por meio de processos de institucionalização que não podem ser considerados totalmente reprodutores, nem totalmente inovadores.

\section{Conclusão}

O Projeto ICSEM, com sua amplitude mundial, desafiou os pesquisadores envolvidos a colocarem distintas realidades em diálogo, respeitando especificidades, mas também encontrando ou construindo pontos de convergência que permitissem a ampliação de conceitos e tipologias existentes. Inicialmente, coube destacar a principal diferença entre as tradicionais abordagens de empresa social - norte-americana e europeia - que consiste no fato de a primeira permitir a definição de empresas de 
mercado com fins lucrativos como empresa social, evidenciando uma implícita normatividade em torno da lógica mercantil. Já a segunda considera as múltiplas dimensões dos critérios estipulados para a empresa social (social, econômica e política), com ênfase à governança interna.

Na análise dos EES à luz destas abordagens, evidenciou-se que os EES, pautados em princípios de solidariedade e de ação coletiva e autogestionária, se distinguem da abordagem norte-americana, principalmente devido à pluralidade de princípios econômicos que os caracterizam, alargando o leque de possíveis variações de empresa social. Nesta abordagem, a normatividade se apóia teoricamente na atual corrente de pensamento que concebe a economia como sinônimo de economia de mercado, denominada porPolanyi (2007) de perspectiva formal. O autorreferese a essa confusão permanente entre economia e mercado como "falácia econômica”, pois o ímpeto acumulativo através do lucro é avaliado positivamente semquestionamento dos seus efeitos. No entanto, em um nível empírico, o formalismo já produziu efeitos perversos.

O exemplo do microcrédito mostra como a busca de autofinanciamento através do mercado e uma preferência por empréstimos individuais - em detrimento dos solidários - excluem muitos indivíduos do acesso a recursos (Servet,2006) e conduzem ao risco de endividamento (Guérin, MorvantRoux \& Villareal, 2013). Neste caso, observa-se com perplexidade a representação heróica do empreendedor social que têm a capacidade de transformar o mundo (Bornstein,2004), espalhando um negócio social que funciona em conformidade com princípios de gestão de uma empresa tradicional e com o propósito de cobrir completamente os seus custos (Yunus,2008). A literatura norte-americana sobre empresa social entrelaça as dimensões analíticas e operacionais, conduzindo a um isomorfismo com o mercado ao recomendar a importação de métodos de gestão privados ou favorecer uma abordagem psicológica e individualizante para o empreendedorismo social.

Quanto à abordagem europeia, a referida multidimensionalidade, a pluralidade de princípios econômicos e a ênfase na governança democrática possibilitaram queos EES se aproximassem do Modelo EMES.Contudo, ao serem analisados através dos indicadores e critérios deste Modelo utilizado como referência no Projeto ICSEM - os EES apresentaram significativas diferençasno objetivo de transformação e reparação, na informalidade predominante, na dimensão pública(concebida como instituinte)e na coerência de seu compromisso social, ambiental e econômico.Ressalta-se ainda um traço distintivo, que consiste no fato de os próprios excluídos serem protagonistas e beneficiários da atividade econômica que lhes oportuniza enfrentar a exclusão àqual se encontramsubmetidos. Esta característica repercute na concepção de missão social, a qual passa a ser indissociável da econômica, não sendo possível distingui-las. Com isso, não haveria, em princípio, objeção à apropriação dos resultados econômicos pelos sócios, muito antes pelo contrário, seria algo desejável.Ademais, o método de autogestão utilizado no EES é uma 
importante dimensão política instituinte e que poderálevar a futuras revisões e ampliações conceituais e tipológicas.

O estudo conclui que o EES é um caso de empresa social. No entanto,não se pode ignorara existência de realidades tão distintas na teorização em curso sobre empresa social, em especial porque predominam referenciais produzidos a partir de experiências típicas do Norte.Neste sentido, por um lado, a aplicação dos indicadores da EMES oportunizou a criação de um modelo para EES a partir de uma metodologia semelhante à definição de empresa social, a qual é amplamente utilizada na Europa. Por outro lado, o EES complementou e contribuiu para a ampliação do Modelo EMES, possibilitando, em última instância, uma dimensão mais ampla e multicultural na análise teórica das empresas sociais.

\section{Agradecimientos}

O artigo é produto de reflexões entre pesquisadores vinculados ao "International Comparative Social Enterprise Models (ICSEM) Project. 


\section{Bibliografía}

Arendt, H. (1999). O que é política? Rio de Janeiro, Brasil: Bertrand Brasil.

Austin, J. E, Leonard, B., Reficco, E. e Wei-Skillern, J. (2006). Social entrepreneurship: it's for corporations too. En Nicholls, A. (Ed.), Social Entrerpreneurship, new models of sustainable social change (pp. 169-80). Oxford, Inglaterra: Oxford University Press.

Blanc, J. e Fare, M. (2012). Les monnaies sociales en tant que dispositifs innovants: une évaluation. En Innovations sociales, $n^{\circ} 3,67-84$. Recuperado de https://www.cairn.info/revue-innovations-2012-2-page-67.htm

Bornstein, D. (2004). How to change the world: social enterpreneurs and the power of new ideas. New York, Estados Unidos: Oxford University Press.

Cattani, A., Hespanha, P., Gaiger, L. e Laville, J-L. (Ed.) (2009). Dicionário internacional da outra economia. Coimbra, Portugal: Almedina.

Coraggio, J. L. (2002). La gente o el capital: desarollo local y economia del trabajo.Buenos Aires, Argentina: Espacio Editorial.

Dees, J-G. (1998). Enterprising nonprofits. Harvard Business Review, 76(1), 54-67. Recuperado de https://www.ncbi.nlm.nih.gov/pubmed/ 10176919

Defourny, J. (2009). Empresa social. En Cattani, A., Gaiger, L., Hespanha, P. e Laville; J-L. (Ed.), Dicionário internacional da outra economia (pp.156-161). Coimbra, Portugal: Almedina.

Defourny, J., Develtere P. e Fonteneau, B. (2001). La economia social en el norte y en el sur. Buenos Aires, Argentina: Corregidor.

Defourny, J. e Nyssens, M.(2013). L’approche EMES de l'entreprise social dans une perspective comparative. SOCENT Working Paper 2013/01. Recuperado de https://emes.net/publications/workingpapers/lapproche-emes-de-lentreprise-sociale-dans-une-perspectivecomparative/

Ferrarini, A. (2016). O ethos da inovação social: implicações ético-políticas para o estudo de práticas produzidas em diferentes ambientes. Revista Contemporânea, 6(2), 477-466. Recuperado de http:// www.contemporanea.ufscar.br/index.php/contemporanea/article/ view/430

Fonteneau, B. et al. (2011). Economía social y solidaria: nuestro camino común hacia el trabajo decente. Turin, Itália: Centre international de formation de l'OIT. 
França Filho, G.; Laville, J-L. (2004). Economia solidária: uma abordagem internacional, Porto Alegre, Brasil: Editora da UFRGS.

França Filho, G. (2006). Políticas públicas de economia solidária no Brasil: características, desafios e vocação. En França Filho, G. C., Laville, JL. et al (Ed.), Ação Pública e economia solidária: uma perspectiva internacional (pp. 259-267). Salvador, Brasil: EDUFBA.

Fraser, N. (2011). Mercantilização, proteção social e emancipação: as ambivalências do feminismo na crise do capitalismo. Revista Direito $G V, 7(2), 617-634$. Recuperado de http://www.scielo.br/ scielo.php?pid=S1808-24322011000200011\&script $=$ sci_abstract\&tlng=pt

Gaiger, L. (2006). Entreprise solidaire. En Laville; J-L. e Cattani, A. Dictionnaire de l'autre économie (pp. 345-357). Paris, França: Gallimard Folio.

Gaiger, L. (2013). O Mapeamento nacional e o conhecimento da economia solidária. Revista da ABET, $\mathrm{n}^{\circ} 12,7-24$. Recuperado de http:// periodicos.ufpb.br/index.php/abet/article/view/18512

Gaiger, L.e Laville, J-L. (2009). Economia solidária. En Cattani, A., Hespanha, P., Gaiger, L. e Laville, J-L. (Ed.), Dicionário internacional da outra economia (pp. 162-168). Coimbra, Portugal: Almedina.

Gaiger, L. I. e Correa, A. (2010). O microempreendorismo em questão: elementos para um modelo alternativo. Política \& Sociedade, 9(17), 205-230. Recuperado de http://revistas.unisinos.br/index.php/ ciencias_sociais/article/viewFile/615/234

Guérin, I., Morvant-Roux, S. e Villarreal, M. (Ed.). (2013). Microfinance, debt and over-indebtedness: juggling with money. New York, Estados Unidos: Routledge.

Hillenkamp, I. e Bessis, F. (2012). L’innovation sociale par l'économie solidaire en Bolivie: une démocratisation des conventions de production et de genre. Innovations sociales, $n^{\circ} 38$. Recuperado de https://www.cairn.info/revue-innovations-2012-2-page-85.htm

Hillenkamp, I. (2013). Le principe de householding aujourd' hui. Discussion théorique et approche empirique parl' économie populaire, En Hillenkamp, I.; Laville, J-L. (Ed.), Socioéconomie et démocratie. L’actualité de Karl Polanyi (pp. 215-39). Toulouse, França: Erès.

Hulgård, L. (2010). Discourses of social entrepreneurship: variations of the same theme? Working Papers Series, no. 10/01. Liege: EMES European Research Network. Recuperado de http://base.socioeco.org/ docs/wp_10-01_hulg_rd_web_.pdf 
Lawrence, T-B. e Suddaby, R. (2006). Institutions and institutional work. En Stewart R. Clegg, Cynthia Hardy, Thomas B. Lawrence e Walter R. Nord (Eds.) Handbook of organization studies. London, England: England Sage. Recuperado de https://thomaslawrence. files.wordpress.com/2008/08/lawrence-and-suddaby-2006institutions-and-institutional-work.pdf

Lévy, D. e Scully, M. The institutional entrepreneur as modern prince : the strategic fact of power incontested fields, Organization Studies, 28(07), 971-991. Recuperado de http://journals.sagepub.com/doi/abs/ 10.1177/0170840607078109

Losekann, C. (2009). A esfera pública habermasiana, seus principais críticos e as possibilidades do uso deste conceito no contexto brasileiro. Pensamento Plural (04), 37-57. Recuperado de http:// pensamentoplural.ufpel.edu.br/edicoes/04/02.pdf

Nyssens, M. (1996). Popular economy in the South, third sector in the North: seeds of a mutually supportive sector? En Sauvage, P. (Ed.), Reconciling economy and society. Towards a plural economy (pp. 91-115). Paris, França: OECD.

Ostrom, E. (2005). Understanding institutional diversity. Princeton, Estados Unidos: Princeton University Press.

Pinheiro, D. C. (2016). O estado da arte da produção científica em economia solidária. Administração Pública e Gestão Social, 8(2), 95-103. Recuperado de http://www.apgs.ufv.br/index.php/apgs/article/view/843/ pdf\#.Wq11qGrwbIU

Polanyi, K. (2007). Le sophisme économiciste. Revue du MAUSS semestrielle, avec K. Polanyi, contre la société du tout marchand, $\mathrm{n}^{\circ}$ 29. Recuperado de http://www.journaldumauss.net/ spip.php?page=imprimer\&id_article $=137$

Polanyi, K. (1975). L’économie en tant que procès institutionnalisé. En Polanyi, K.; Conrad, M. ePearson, H. (Ed.), Les systèmes économiques dans l'histoire et dans la théorie (pp. 239-260). Paris, França: Larousse Université.

Polanyi, K. (2011). La subsistance de l'homme. La place de l'économie dans l'histoire et la société (traduit et présenté par B. Chavance). Paris, França: Flammarion.

Prahalad, C. K. (2004). Fortune at the bottom of the pyramid. Paris, França: Ed. Village Mondial. 
Quéinnec, E. (2007). La croissance des ONG humanitaires, une innovation devenue institution. Revue française de gestion, 33 (117), 83-94. DOI: 10.3166/rfg.177.83-94

Razeto, L. (1993). Empresas de trabajadores y economia de mercado. Santiago, Chile: Programa de Economia del Trabajo, Academia de Humanismo Christiano.

Rival, M.; Eynaud, P. e Gautier, A. (2008). Associations et entrepreneuriat institutionnel. En Jean-Louis Laville e Christian Hoarau (Ed.), La gouvernance des associations. Économie, sociologie, gestion (pp. 215-225). Tolouse, França: ERES. DOI: 10.3917/ eres.lavil.2008.01.0215

Salamon, M. D. e Young, D. (2002). The state of nonprofit America. Washington D. C., Estados Unidos: Brookings Institution.

Sarria Icaza, A. e Tiriba, L. (2006). Économie populaire. En Laville, J-L. e Cattani, A. D. (Ed.), Dictionnaire de l'autre économie (pp. 258-268). Paris, França: Gallimard.

Servet, J-M. (2006). Banquiers aux pieds nus. La microfinance. Paris, França: Odile Jacob.

Servet, J-M. (2013). Le principe de réciprocité au jourd’hui. Un concept pour comprendre et construirel' économie solidaire. En Hillenkamp, I. e Laville, J-L. (Ed.), Socioéconomie et démocratie. L'actualité de Karl Polanyi (pp. 187-213). Toulouse, França: Erès.

Singer, P. (2006). Economie solidaire. En Laville, J-L. e Cattani, A. (Ed.), Dictionnaire de l'autre économie (pp. 290-302). Paris, França: Gallimard Folio.

Soto, H. (1997). L’autre sentier. La révolution informelle. Paris, França: La Découverte.

Van Griethuysen, P. (2010). Pourquoi le développement durable s’est-il imposé là où l'écodéveloppement a échoué? Débats pour la suite du monde. En Yves-Marie, A; Louis, M. e Herve, P. (Ed.), Développement durable ou décroissance soutenable? (pp. 60-79). Montréal, Canadá: Ecosociété.

Veronese, M.; Gaiger, L.; Ferrarini, A. Sobre a diversidade de formatos e atores sociais no campo da economia solidária. Caderno CRH, 30(79), 89-104. Doi: 10.1590/s0103-49792017000100006

Wanderley, F. (2009). Crecimiento, empleo y bienestar social ¿Por qué Bolivia es tan desigual? La Paz, Bolívia: Plural. 
Polis, Revista Latinoamericana, $N^{\circ}$ 49, 2018

Yunus, M. (2008). Vers un nouveau capitalisme. Paris, França: Jean-Claude Lattes.

Recibido:27.05.17

Aceptado: 31.01 .18 